\title{
Clonagem e purificação de fragmento da proteína capsidial de Banana streak OL virus
}

\author{
Ricardo Lombardi(1), Ricardo Harakava(1) e Addolorata Colariccio(1) \\ (1)Instituto Biológico, Avenida Conselheiro Rodrigues Alves, no 1.252, CEP 04014-002 São Paulo, SP. E-mail: ricardolombardii@hotmail.com, \\ harakava@biologico.sp.gov.br, colariccio@biologico.sp.gov.br
}

Resumo - O objetivo deste trabalho foi clonar e induzir a expressão de fragmento da proteína capsidial de Banana streak OL virus (BSOLV-CP) em Escherichia coli, bem como purificar a proteína recombinante obtida. Empregou-se um par de iniciadores específicos para amplificar, em PCR, um fragmento de aproximadamente $390 \mathrm{pb}$, da região codificadora da porção central da BSOLV-CP. O fragmento obtido foi clonado em vetor pGEM-T Easy, subclonado em vetor pQE-30 e transformado em células de E. coli M15 (pREP4) por choque térmico. A expressão da proteína foi induzida por tiogalactopiranosídeo de isopropila (IPTG), e a proteína recombinante BSOLV-rcCP de $14 \mathrm{kDa}$ foi detectada em Western blot e Dot blot. A expressão da proteína BSOLV-rcCP abre novas possibilidades para a obtenção de antígenos para a produção de antissoros contra o BSOLV.

Termos para indexação: Badnavirus, Escherichia coli, Musa, antissoro, bananeira, expressão de proteínas recombinantes.

\section{Cloning and purification of Banana streak $O L$ virus coat protein fragment}

\begin{abstract}
The objective of this work was to clone and to induce the expression of a fragment of Banana streak $O L$ virus coat protein (BSOLV-CP) in Escherichia coli, as well as to purify the obtained recombinant protein. Two specific primers were used for the PCR-amplification of approximately 390-bp fragment of the codifying region of the BSOLV-CP central portion. The obtained fragment was cloned in pGEM-T Easy vector, subcloned in pQE-30 expression vector and transformed into competent $E$. coli M15 (pREP4) cells by heat shock. The protein expression was induced by isopropyl thiogalactopyranoside (IPTG) and the 14-kDa BSOLV-rcCP recombinant protein was detected in Western and Dot blotting. The expression of the BSOLV-rcCP protein enables new approaches to the obtention of antigens for the antisera production against BSOLV.
\end{abstract}

Index-terms: Badnavirus, Escherichia coli, Musa, antisera, banana plant, recombinant protein expression.

\section{Introdução}

Abananeiraéuma planta herbácea, monocotiledônea, pertencente ao gênero Musa (Musaceae, Zingiberales) (Heslop-Harrison \& Schwarzacher, 2007). O Brasil figura atualmente como o quarto maior produtor de bananas do mundo (Food and Agriculture Organization of the United Nations, 2007).

A micropropagação in vitro da bananeira consiste na melhor opção para a obtenção de mudas, por possibilitar a multiplicação em qualquer época do ano e promover aumento da produção (Oliveira et al., 2001). No Brasil, o Banana streak virus (BSV) foi primeiramente descrito em bananeiras por Brioso et al. (2000) e, posteriormente, por Marinho \& Batista (2005), em mudas de bananeira provenientes de cultura de meristemas, importadas da Costa Rica.
O BSV tem partículas baciliformes com largura constante de $30 \mathrm{~nm}$ e comprimento que varia de 120 a $150 \mathrm{~nm}$ (Hull et al., 2005). Seu genoma é composto de DNA circular de fita dupla, com tamanho aproximado de $7,4 \mathrm{~kb}$ e três ORFs ("open reading frames"). As estruturas ORF I e ORF II, potencialmente, codificam duas pequenas proteínas de funções desconhecidas com 22,8 e $14,5 \mathrm{kDa}$, respectivamente. A ORF III codifica uma poliproteína de $208 \mathrm{kDa}$ que consiste de uma provável proteína de movimento célula a célula, uma proteína capsidial, uma protease aspártica e uma replicase viral, que tem funções de transcriptase reversa e de ribonuclease $\mathrm{H}$. Acredita-se que essa poliproteína seja clivada, após sua transcrição, em suas unidades funcionais, pela protease aspártica (Harper \& Hull, 1998). 
Os métodos para detecção do BSV são: a inspeção por sintomas, que podem ser confundidos com os causados pelo Cucumber mosaic virus; microscopia eletrônica; ELISA ("enzyme-linked immunosorbent assay"); e PCR ("polimerase chain reaction") (Harper et al., 1999). Foram desenvolvidos ensaios para a detecção do BSV por PCR multiplex (Figueiredo \& Brioso, 2007) e por imunocaptura seguida de reação de PCR (IC-PCR) (Harper et al., 1999; Le Provost et al., 2006).

Ndowora et al., 1999, comprovaram a presença, no genoma da bananeira, de EPRV ("endogenous pararetroviral sequences") que são sequências virais integradas ao genomas de plantas. Para o genoma da bananeira, já foram descritos dois tipos de EPRV relacionados ao BSV: um tipo que contém o genoma completo do vírus e que pode originar partículas virais e causar infecção epissomal; e outro tipo com sequências incompletas do BSV, não relacionadas à manifestação da doença (Jaufeerally-Fakim et al., 2006). A hipótese de que a propagação in vitro pode atuar como desencadeadora da infecção a partir das EPRV ganhou força com estudos realizados por Dallot et al. (2001) e Côte et al. (2010), ainda que os mecanismos para que tal evento ocorra não sejam entendidos.

O BSV tem causado grande preocupação nos últimos anos, em razão do aumento de relatos de infecção nas linhagens de bananeira e híbridos micropropagados (Le Provost et al., 2006). Genótipos resultantes de cruzamentos entre $M$. acuminata e $M$. balbisiana, inclusive uma variedade de novos híbridos, mostraram a tendência de produzirem propágulos infectados pelo BSV, mesmo quando são utilizadas plantas assintomáticas na cultura de tecidos (Dallot et al., 2001).

Para a detecção da infecção epissomal e da possível ativação das sequências do BSV integradas à bananeira, há a necessidade de produção de antissoros que possam detectar os diferentes isolados do vírus. Atualmente, a expressão e purificação de proteínas virais recombinantes em Escherichia coli são uma alternativa para a obtenção de antígenos para a produção de antissoros (Radaelli et al., 2008). Para o BSOLV, ainda não foi realizada a produção e purificação da proteína capsidial recombinante.

O objetivo do presente trabalho foi clonar e induzir a expressão, em $E$. coli, de um sítio antigênico da região central da capa proteica do Banana streak $O L$ virus (BSOLV-rcCP), e sua purificação.

\section{Material e Métodos}

Neste trabalho foram empregadas folhas de bananeira (Musa sp.), cultivar Terra Anã, procedente de São José dos Campos, SP, com sintomas de estrias foliares, mosaico e lesões foliares cloróticas.

Foram desenhados dois iniciadores específicos BSVOL-CP2/R (antissenso 5'- AAG CTT GGA TAA TTC TTC TGA GG -3', Hind III) e BSVOL-CP2/F (senso 5'- GAG CTC ATT ACC CTC CTA CAC AT -3', Sst I) - de acordo com a sequência depositada no GenBank, número de acesso AJ_002234.1, para amplificar a região codificadora de 386 pb de um sítio antigênico, da região central da capa proteica do BSOLV (BSOLV-CP), em PCR. Para a obtenção do sítio antigênico, foi empregado o programa "Antibody Epitope Prediction" (Peters et al., 2005).

A extração de DNA total das folhas de bananeira foi realizada pelo método CTAB (brometo de cetiltrimetilamônio) (Dellaporta et al., 1983). Para a amplificação do fragmento da BSOLV-CP, utilizouse o kit GoTaq DNA polymerase (Promega, Madison, EUA). Foram misturados, em tubo de polipropileno para PCR, $10 \mu \mathrm{L}$ de 5X GoTaq Reaction Buffer (Promega, Madison, EUA), $1 \mu \mathrm{L}$ de mistura de dNTPs (10 mmol L-1 cada dNTP), $1 \mu \mathrm{L}$ de iniciador senso $\left(20 \mu \mathrm{ML}^{-1}\right), 1 \mu \mathrm{L}$ de iniciador antisenso $\left(20 \mu \mathrm{ML}^{-1}\right)$, $0,2 \mu \mathrm{L}$ GoTaq DNA polymerase $\left(5 \mathrm{U}^{-1} \mathrm{~L}^{-1}\right)$ (Promega, Madison, EUA), $2 \mu \mathrm{L}$ (aproximadamente $10 \mathrm{ng}$ ) de DNA molde, e água destilada deionizada estéril para $50 \mu \mathrm{L}$. A reação foi conduzida em termociclador PTC-100 (MJ Research Inc., Watertown, EUA). As temperaturas e tempos de incubação foram: $94^{\circ} \mathrm{C}$, por $2 \mathrm{~min}$; 40 ciclos de $94^{\circ} \mathrm{C}$ por $30 \mathrm{~s}, 56^{\circ} \mathrm{C}$ por $30 \mathrm{~s} \mathrm{e}$ $72^{\circ} \mathrm{C}$ por $60 \mathrm{~s} ; 72^{\circ} \mathrm{C}$ por $4 \mathrm{~min}$; e $4^{\circ} \mathrm{C}$ até a utilização da amostra. A presença do produto amplificado foi confirmada por eletroforese em gel de agarose a $1,5 \%$ em tampão TAE $\left(40 \mathrm{mmol} \mathrm{L}^{-1}\right.$ Tris acetato, $2 \mathrm{mmol} \mathrm{L}^{-1}$ EDTA), com brometo de etídeo $\left(1 \mu \mathrm{g} \mathrm{L}^{-1}\right)$, e visualizada sob luz ultravioleta em fotodocumentador AlphaImager TM 1220 (Alpha Innotech, San Leandro, EUA).

Para remoção de iniciadores, dNTP e sais dos produtos obtidos na PCR, foi realizada uma purificação com o kit QIAquick PCR Purification (QIAGEN, Valencia, 
EUA), conforme indicação do fabricante. O produto de DNA amplificado e purificado foi inserido no vetor pGEM-T Easy (Promega, Madison, EUA), conforme protocolo do fabricante: foram misturados $5 \mu \mathrm{L}$ de $2 X$ Rapid Ligation Buffer (Promega, Madison, EUA), T4 DNA ligase, $1 \mu \mathrm{L}$ pGEM-T Easy (50 ng), $3 \mu \mathrm{L}$ do produto purificado da PCR, $1 \mu \mathrm{L}$ T4 DNA ligase, e a reação foi incubada por 1 hora a temperatura ambiente.

O vetor com o inserto foi, então, inserido nas células competentes de Escherichia coli DH10B, por meio de transformação via choque térmico, em que as células foram misturadas ao vetor, com permanência de exatamente $1 \mathrm{~min}$ a $42^{\circ} \mathrm{C}$, seguida de $2 \mathrm{~min}$ em gelo. Foi adicionado $1 \mathrm{~mL}$ de meio de cultura Circlegrow (CG) (Qbiogene), e as bactérias foram incubadas sob agitação por 1 hora a $37^{\circ} \mathrm{C}$.

$\mathrm{O}$ meio com as bactérias foi centrifugado a $10.000 \mathrm{~g}$, e aproximadamente $850 \mu \mathrm{L}$ do sobrenadante foi descartado. As bactérias foram suspendidas e plaqueadas em meio Luria-Bertani (LB) sólido, (Fischer-Biotech, Adelaide, Australia), com ampicilina $\left(100 \mu \mathrm{g} \mathrm{mL}^{-1}\right)$ e X-gal ( $4 \mu \mathrm{L}$ de solução $\left.20 \mathrm{mg} \mathrm{mL}^{-1}\right)$ e incubadas a $37^{\circ} \mathrm{C}$, por 16 horas. Após o crescimento, as colônias brancas foram cultivadas em meio CG, por 24 horas a $37^{\circ} \mathrm{C}$, sob agitação e, então, submetidas a uma mini-preparação "Wizard Plus SV Minipreps DNA Purification Systems" (Promega, Madison, EUA), para a purificação dos plasmídeos, conforme indicação do fabricante.

O fragmento clonado em pGEM-T Easy foi submetido à reação de sequenciamento automático pelo sistema Big Dye Terminator - Cycle Sequencing Ready Reaction (Applied Biosystems), pelo método de terminação de cadeia (Sanger et al., 1977). A reação de sequenciamento foi analisada em aparelho ABI 377 (Applied Biosystems, California, EUA), e a sequência de nucleotídeos foi submetida ao programa "Basic Local Alignment Search Tool" (BLAST), (Altschul et al., 1990).

$\mathrm{O}$ vetor construído pGEM-T Easy + BSOLV-CP e o vetor de expressão pQE-30 (QIAGEN, Valencia, EUA) foram submetidos à digestão com as enzimas de restrição Hind III e Sst I, por 2 horas, a $37^{\circ} \mathrm{C}$, para obtenção de extremidades compatíveis. Os produtos da reação foram submetidos à eletroforese em gel de agarose, a 1,5\%, e observados sob luz ultravioleta, em aparelho Eletronic U.V. Transluminator (Ultra-Lum,
Claremont, EUA), em intensidade baixa. As bandas correspondentes ao inserto BSOLV-CP e ao vetor $\mathrm{pQE}-30$ foram excisadas do gel e purificadas com o kit PureLink Quick Gel Extraction (Invitrogen), segundo indicação do fabricante.

A reação de ligação entre o vetor $\mathrm{pQE}-30$ e o inserto BSOLV-CP foi realizada conforme protocolo do fabricante (Quiagen, Valencia, EUA). O vetor pQE-30 $(1 \mu \mathrm{L})$ e o inserto $(3 \mu \mathrm{L})$ digeridos foram misturados a $5 \mu \mathrm{L}$ de $2 X$ Rapid Ligation Buffer e $1 \mu \mathrm{L}$ T4 DNA ligase. A reação foi incubada por 16 horas a $16^{\circ} \mathrm{C}$. Células competentes de E. coli M15 (pREP4) foram transformadas com a construção pQE-30 + BSOLV-CP, por meio de choque térmico, na forma descrita anteriormente. As bactérias foram plaqueadas em meio LB sólido com ampicilina $\left(100 \mu \mathrm{g} \mathrm{mL}^{-1}\right)$ e canamicina $\left(25 \mu \mathrm{L} \mathrm{mL}^{-1}\right)$, e mantidas a $37^{\circ} \mathrm{C}$ por 24 horas. Após crescimento, as colônias foram cultivadas em $2 \mathrm{~mL}$ de meio CG com ampicilina (100 $\left.\mu \mathrm{g} \mathrm{mL}^{-1}\right)$ e canamicina $\left(25 \mu \mathrm{L} \mathrm{mL}^{-1}\right)$, por 16 horas, sob agitação para, então, serem submetidas à extração de DNA plasmidial, conforme descrito anteriormente.

Foram selecionados 16 clones de E. coli $\mathrm{M} 15$ (pREP4), que continham a construção pQE-30 + BSOLV-CP. Cada clone foi cultivado em $2 \mathrm{~mL}$ de meio $\mathrm{CG}$ com ampicilina $\left(100 \mu \mathrm{g} \mathrm{mL}^{-1}\right)$ e canamicina $\left(25 \mu \mathrm{g} \mathrm{mL}^{-1}\right)$ por $30 \mathrm{~min}$. A expressão da proteína recombinante BSOLV-rcCP foi induzida pela adição de tiogalactopiranosídeo de isopropila (IPTG), à concentração final de $1 \mathrm{mmol} \mathrm{L}^{-1}$, por 16 horas. As células bacterianas foram sedimentadas por centrifugação a $10.000 \mathrm{~g}$, lisadas em tampão de lise $\left(60 \mathrm{mmol} \mathrm{L}^{-1}\right.$ Tris- $\mathrm{HCl}$ $\mathrm{pH} 6,8,5 \%$ glicerol, $2 \%$ SDS, 4\% $\beta$-mercaptoetenol). Foi empregado Dot blot, para verificar a presença e o melhor nível de expressão da proteína BSOLV-rcCP. Como controle positivo, foi utilizado um clone que continha a construção BSOLV-rcCP induzido e, como negativo, um clone não induzido.

Para o isolamento da proteína BSOLV-rcCP, foi realizada a purificação da proteína expressa em clone selecionado de E. coli M15 (pREP4), em coluna de níquel-agarose, conforme protocolo HisTrap HP Kit (GE Health Care Bio-Sciences, Piscataway, EUA), sob condições desnaturantes de ureia $8 \mathrm{mmol} \mathrm{L}^{-1}$. Um volume de $100 \mathrm{~mL}$ de cultura bacteriana induzida com IPTG, à concentração final de $1 \mathrm{mmol} \mathrm{L}^{-1}$, durante 16 horas, foi centrifugado a $7.000 \mathrm{~g}$ por 15 min, e o precipitado foi suspendido em tampão de lise 
(20 mmol L-1 fosfato de sódio, $8 \mathrm{~mol} \mathrm{~L}^{-1}$ ureia, $\mathrm{pH} 7,4$ ). Todas as frações da lavagem da coluna, eluição da proteína e do lisado bacteriano bruto foram coletadas e submetidas à SDS-PAGE, Western blot e Dot blot, para localização da fração da proteína eluída.

A fração com a proteína BSOLV-rcCP purificada foi aplicada em gel desnaturante de poliacrilamida (gel concentrador $4 \%$ e gel de separação 12\%), submetida à eletroforese, e corada com solução aquosa de Coomassie Brilliant Blue R-250 0,05\% (Bio-Rad Laboratories, Richmond, EUA), por 1 hora. $\mathrm{O}$ gel foi descorado com lavagens sucessivas de água destilada deionizada até a visualização da banda correspondente à proteína BSOLV-rcCP. A banda foi excisada do gel e homogeneizada com igual volume de água destilada deionizada.

Para a separação das proteínas e localização da proteína BSOLV-rcCP, alíquotas do lisado bacteriano bruto e das frações purificadas da BSOLV-rcCP foram submetidas à eletroforese em gel desnaturante de poliacrilamida (SDS-PAGE) (gel concentrador 4\% e gel de separação $12 \%$ ) com equipamento para eletroforese vertical Mini Protean II (Bio-Rad Laboratories, Richmond, EUA). Foi utilizada a solução BenchMark Prestained Protein Ladder (Invitrogen Brasil Ltda., São Paulo, Brasil), como marcador de massa molecular pré-corado. $\mathrm{O}$ gel foi submetido a $200 \mathrm{~V}$, por $45 \mathrm{~min}$. Em seguida, o gel foi incubado em solução corante (50\% metanol, 10\% ácido acético, $40 \%$ água destilada, 0,05\% Coomassie Brilliant Blue R-250), por duas horas, e descorado com sucessivas lavagens de solução descorante (7\% ácido acético, 5\% metanol, 88\% água destilada). Para o Western blot, as proteínas presentes em um gel não corado foram transferidas para a membrana de nitrocelulose, em sistema semisseco, com uso do equipamento Trans-blot SD (Bio-Rad), por $30 \mathrm{~min}$.

Após a transferência, a membrana foi incubada em solução bloqueadora $\left(100 \mathrm{mmol} \mathrm{L}^{-1}\right.$ Tris $\mathrm{HCl} \mathrm{pH}$ 7,5, $0,9 \% \mathrm{NaCl}, 1 \%$ leite desnatado, $1 \%$ Tween- 20 ) a $37^{\circ} \mathrm{C}$. Após 30 minutos, a membrana foi lavada duas vezes com tampão TTBS (100 mmol L-1 Tris $\mathrm{HCl}$ pH 7,5, $0,9 \% \mathrm{NaCl}, 1 \%$ Tween-20), seguida de incubação por 1 hora a $37^{\circ} \mathrm{C}$ com antissoro anti-6xHis (GE Healthcare Bio-Sciences, Piscataway, EUA) (1:1.000 em TTBS). Após o período de incubação, a membrana foi lavada duas vezes com TTBS e incubada com o conjugado antimouse-fosfatase alcalina (Sigma Chemical, St. Louis, EUA) (1:30.000 em TTBS), por 1 hora a $37^{\circ} \mathrm{C}$.
A membrana foi lavada duas vezes com TTBS, seguida de uma lavagem de TBS $\left(100 \mathrm{~m} \mathrm{~mol} \mathrm{~L}^{-1}\right.$ Tris $\mathrm{HCl} \mathrm{pH}$ $7,5,0,9 \% \mathrm{NaCl})$. Finalmente, a membrana foi revelada com BCIP/NBT ("bromochloroindolyl phosphate"/ "nitrobluetetrazolium").

Para o Dot blot dos 16 clones lisados em tampão de lise, do lisado bacteriano bruto e das frações da purificação da proteína BSOLV-rcCP, alíquotas de $2 \mu \mathrm{L}$ foram depositadas sobre membrana de nitrocelulose e secas em estufa a $37^{\circ} \mathrm{C}$ por $20 \mathrm{~min}$. A membrana foi submetida à mesma metodologia seguida no Western blot.

\section{Resultados e Discussão}

Foi amplificado, em PCR, um produto de aproximadamente $390 \mathrm{pb}$, conforme o esperado para o fragmento BSOLV-rcCP (Figura $1 \mathrm{~A}$ ). Após sequenciamento e submissão ao programa BLAST, a sequência de nucleotídeos amplificada apresentou $100 \%$ de similaridade com a sequência do BSOLV depositada no GenBank, número de

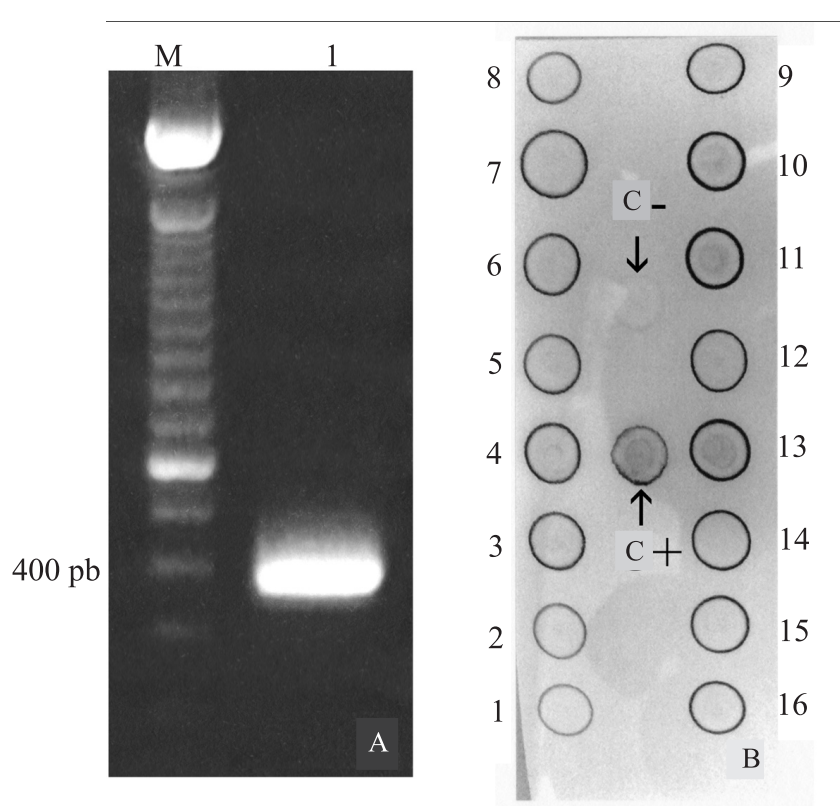

Figura 1. Fragmento com aproximadamente 390 pb (1), correspondente ao BSOLV-rcCP (A). M, marcador de peso molecular com 1.000 pb DNA ladder (Invitrogen, Carlsbad, EUA). Dotblot dos 16 clones selecionados de Escherichia coli M15, com a construção pQE-30 + BSOLV-CP, após indução da expressão da proteína (B). Nos clones 10, 11 e 13 ocorreu a formação de halo mais intenso. C-, controle negativo; $\mathrm{C}+$, controle positivo. 
acesso AJ_002234.1. O fragmento obtido corresponde à região codificadora de um sítio antigênico, da região central da proteína capsidial do BSOLV. O algoritmo que prediz as regiões antigênicas num polipeptídeo, utilizado pela ferramenta Antibody Epitope Prediction (Peters et al., 2005), baseia-se na predição da hidrofilicidade de regiões do polipeptídeo, que está diretamente correlacionada à sua antigenicidade. Estas porções hidrofílicas são regiões mais acessíveis, ou mais expostas do polipeptídeo (Mant et al., 2009).

Após a clonagem, o DNA plasmidial (construção pGEMT-Easy+BSOLV-CP) e o vetor de expressão pQE-30 foram digeridos com as enzimas de restrição Hind III e Sst I, para que extremidades coesivas fossem geradas. O sucesso do procedimento foi confirmado por meio de eletroforese dos produtos da digestão. $\mathrm{O}$ inserto BSOLV-CP e o vetor $\mathrm{pQE}-30$ foram excisados do gel, e ligados. A construção BSOLV-CP+pQE-30 foi transformada em células de Escherichia coli M15 (pREP4), e 16 clones recombinantes foram induzidos para a expressão da proteína e submetidos a Dot blot (Figura $1 \mathrm{~B}$ ). Houve diferenças nos níveis de expressão da proteína, evidenciadas pela formação de um halo de tonalidade diferente. A presença do halo mais escuro significa maior quantidade da proteína BSOLV-rcCP. Foi selecionado o clone 10 para a expressão da proteína.

O lisado bruto da cultura bacteriana (clone 10) e as frações da purificação em coluna de níquel-agarose passagem do lisado bruto pela coluna, lavagens da coluna e eluições da proteína - foram submetidas a Dot blot (Figura 2). Foi possível visualizar, por meio da intensidade da reação, a presença da proteína BSOLV-rcCP, tanto nas frações do lisado bruto como nas frações de eluição da coluna. As frações 4 e 5 apresentaram maior quantidade da proteína.

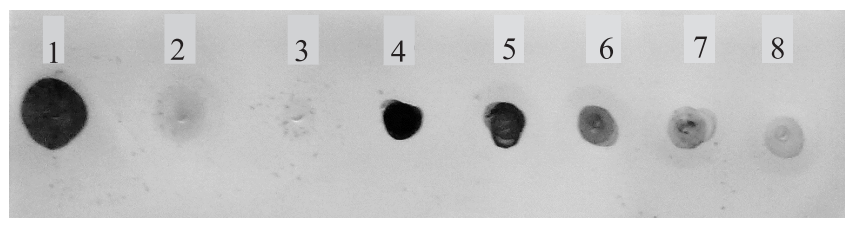

Figura 2. Dot blot das alíquotas do lisado bacteriano e das frações de purificação da proteína BSOLV-rcCP. Observa-se a presença de maior concentração da proteína BSOLV-rcCP no lisado bruto e nas eluições 4 e 5 . 1, Lisado bacteriano bruto; 2, Lisado, após passagem pela coluna; 3, lavagem da coluna; 4 a 8, eluições da proteína BSOLV-rcCP.
Em SDS-PAGE ("sodium dodecyl sulfatepolyacrylamide gel electrophoresis"), observou-se que as frações de eluição continham principalmente uma proteína de aproximadamente $14 \mathrm{kDa}-\mathrm{BSOLV}-\mathrm{rcCP}$ (Figura $3 \mathrm{~A}$ ). Em Western blot, foi possível identificar a proteína BSOLV-rcCP de aproximadamente $14 \mathrm{kDa}$ no lisado bruto e na primeira lavagem da coluna (Figura 3 B). Nas frações de eluição 4 e 5, foi observada a presença da proteína em grande concentração.

O BSV tem uma diversidade genômica e sorológica reconhecida mundialmente e é importante a produção de antissoros para detectar os sorotipos conhecidos do vírus (Agindotan et al., 2003). Atualmente, são aceitos como espécies definitivas pelo ICTV ("International Committee on Taxonomy of

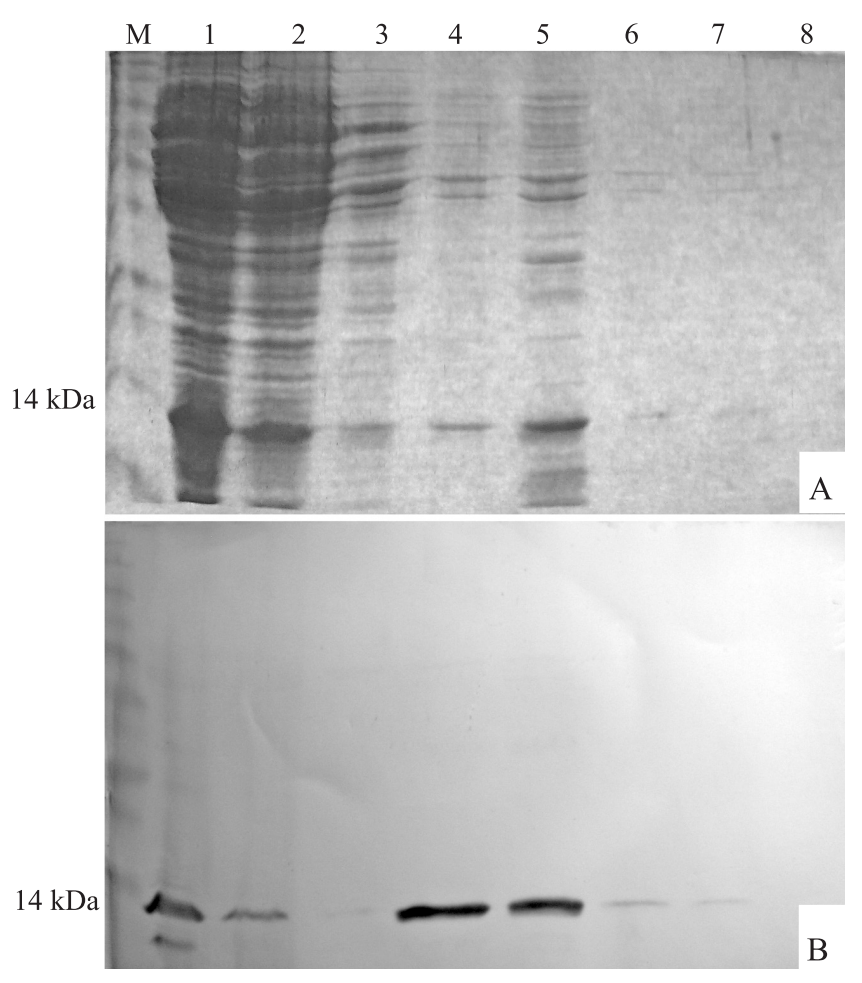

Figura 3. SDS-PAGE (A) e Western blot (B) do lisado bacteriano e das frações da proteína BSOLV-rcCP purificada. Em A, as frações de eluição contêm principalmente uma proteína de aproximadamente $14 \mathrm{kDa}$; em $\mathrm{B}$, observa-se a reação da proteína de $14 \mathrm{kDa}$ com o antissoro anti-6xHis e que as eluições 4 e 5 contêm maior quantidade da proteína BSOLV-rcCP purificada. M, marcador de massa molecular BenchMark Prestained Protein Ladder (Invitrogen, Carlsbad, EUA); 1, lisado bacteriano bruto; 2, lisado, após passagem pela coluna; 3 , lavagem da coluna; 4 a 8 , eluições da proteína BSOLV-rcCP. 
Viruses") três espécies do BSV: o Banana streak Mysore virus, o Banana streak $O L$ virus e o Banana streak $G F$ virus, da família Caulimoviridae, genêro Badnavirus (Hull et al., 2005). Há, ainda, a proposição de outras espécies que se baseiam em diferenças nas sequências de nucleotídeos da ORF III do BSV (Figueiredo et al., 2006; Jaufeerally-Fakim et al., 2006).

Para a detecção do BSV epissomal, foi desenvolvida a metodologia de IC-PCR (Harper et al., 1999; Le Provost et al., 2006), que reduz a possibilidade de se detectarem as sequências do BSV integradas no genoma da bananeira.

Com o número crescente de sequências de nucleotídeos dos isolados e espécies do BSV depositados no GenBank, a produção de proteínas recombinantes em $E$. coli torna-se uma alternativa para a obtenção de antígenos para a produção de antissoros contra o BSV. Uma vez que seja obtido um clone recombinante, este pode ser reproduzido em meio de cultivo, para fornecimento da proteína recombinante em grande escala.

Com base em sequências codificadoras depositadas no GenBank, pode-se produzir uma ampla gama de proteínas recombinantes, para produção de antissoros contra os diversos isolados e espécies do BSV.

\section{Conclusões}

1. A metodologia apresentada é apropriada para a expressão da proteína BSOLV-rcCP, e as etapas de clonagem e purificação da proteína podem ser reproduzidas.

2. A expressão da proteína recombinante BSOLV-rcCP é uma alternativa para a obtenção do antígeno para a produção de antissoros contra o BSOLV.

\section{Agradecimentos}

À Fundação de Amparo à Pesquisa do Estado de São Paulo, por concessão de bolsa.

\section{Referências}

AGINDOTAN, B.O.; THOTTAPPILLY, G.; UWAIFO, A.; WINTER, S. Production of monoclonal and polyclonal antibodies against a Nigerian isolate of Banana streak virus. African Journal of Biotechnology, v.2, p.171-178, 2003.
ALTSCHUL, S.F.; GISH, W.; MILLER, W.; MYERS, E.W.; LIPMANL, D.J. Basic local alignment search tool. Journal of Molecular Biology, v.215, p.403-410, 1990.

BRIOSO, P.S.T.; CORDEIRO, Z.J.M.; REZENDE, J.A.M.; KITAJIMA, E.W.; PIMENTEL, J.P.; FIGUEIREDO, A.R. Infecção mista em bananeiras pelos vírus do mosaico do pepino ("Cucumber mosaic virus" - CMV) e da risca da bananeira ("Banana streak virus" - BSV) no Brasil. Summa Phytopathologica, v.26, p.254-257, 2000.

CÔTE, F.X.; GALZI, S.; FOLLIOT, M.; LAMAGNÈRE, Y.; TEYCHENEY, P.; ISKRA-CARUANA, M.-L. Micropropagation by tissue culture triggers differential expression of infectious endogenous Banana streak virus sequences (eBSV) present in the $\mathrm{B}$ genome of natural and synthetic interspecific banana plantains. Molecular Plant Pathology, v.11, p.137-144, 2010.

DALlOT, S.; ACUÑA, P.; RIVERA, C.; RAMÍREZ, P.; CÔTE, F.; LOCKHART, B.E.L.; CARUANA, M.L. Evidence that the proliferation stage of micropropagation procedure is determinant in the expression of Banana streak virus integrated in the genome of the FHIA 21 hybrid (Musa AAAB). Archives of Virology, v.146, p.2179-2190, 2001.

DELLAPORTA, S.L.; WOOD, J.; HICKS, J.B. A plant DNA minipreparation: version II. Plant Molecular Biology Reporter, v.1, p.19-21, 1983.

FIGUEIREDO, D.V.; BRIOSO, P.S.T. PCR multiplex para a detecção de BSV e CMV em bananeiras micropropagadas. Summa Phytopathologica, v.33, p.229-232, 2007.

FIGUEIREDO, D.V.; CUNHA-JUNIOR, J.O.; NOGUEIRA, M. do S.R.; MONTANO, H.G.; BRIOSO, P.S.T. Diversidade genética do Banana streak virus no Brasil. In: REUNIÃO INTERNACIONAL ACORBAT, 17., 2006, Joinville. Anais. Joinvile: Acorbat, 2006. p.757-763.

FOOD AND AGRICULTURE ORGANIZATION OF THE UNITED NATIONS. Faostat. 2007. Disponível em: <http:// faostat.fao.org >. Acesso em: 27 jul. 2010.

HARPER, G.; DAHAL, G.; THOTTAPPILLY, G.; HULL, R. Detection of episomal banana streak badnavirus by IC-PCR. Journal of Virological Methods, v.79, p.1-8, 1999.

HARPER, G.; HULL, R. Cloning and sequence analysis of Banana streak virus DNA. Virus Genes, v.17, p.271-278, 1998.

HESLOP-HARRISON, J.S.; SCHWARZACHER, T. Domestication, genomics and the future for banana. Annals of Botany, v.100, p.1073-1084, 2007.

HULL, R.; GEERING, A.; HARPER, G.; LOCKHART, B.E.; SCHOELZ, J.E. Family Caulimoviridae. In: FAUQUET, C.M.; MAYO, M.A.; MANILOFF, J.; DESSELBERGER, U.; BALL, A.L. (Ed.). Virus taxonomy: classification and nomenclature of viruses. San Diego: Elsevier, 2005. p.385-396. (Eighth Report of the International Committee on Taxonomy of Viruses).

JAUFEERALLY-FAKIM, Y.; KHORUGDHARRY, A.; HARPER G. Genetic variants of Banana streak virus in Mauritius. Virus Research, v.115, p.91-98, 2006.

LE PROVOST, G.; ISKRA-CARUANA, M.-L.; ACINA, I.; TEYCHENEY, P. Improved detection of episomal Banana streak 
viruses by multiplex immunocapture PCR. Journal of Virological Methods, v.137, p.7-13, 2006.

MANT, C.T.; KOVACS, J.M.; KIM, H.-M.; POLLOCK, D.D.; HODGES, R.S. Intrinsic amino acid side-chain hydrophilicity/ hydrophobicity coefficients determined by reversed-phase high-performance liquid chromatography of model peptides: comparison with other hydrophilicity/hydrophobicity scales. Biopolymers, v.92, p.573-595, 2009.

MARINHO, V.L.A.; BATISTA, M. de F. Interceptação, pelo serviço de quarentena, de vírus em mudas meristemáticas de bananeiras importadas. Fitopatologia Brasileira, v.30, p.552, 2005.

NDOWORA, T.; DAHAL, G.; LA FLEUR, D.; HARPER, G.; HULL, R.; OLSZEWSKI, N.E.; LOCKHART, B.E.L. Evidence that badnavirus infection in Musa can originate from integrated pararetroviral sequences. Virology, v.255, p.214-220, 1999.

OLIVEIRA, R.P. de; SILVEIRA, D.G.; SILVA, S. de O. e. Concentração de BAP e a eficiência de micropropagação de bananeira tetraploide (grupo AAAB). Scientia Agricola, v.58, p.73-78, 2001.

PETERS, B.; SIDNEY, J.; BOURNE, P.; BUI, H.-H.; BUUS, S.; DOH, G.; FLERI, W.; KRONENBERG, M.; KUBO, R.; LUND, O.; NEMAZEE, D.; PONOMARENKO, J.V.; SATHIAMURTHY, M.; SCHOENBERGER, S.; STEWART, S.; SURKO, P.; WAY, S.; WILSON, S.; SETTE, A. The immune epitope database and analysis resource: from vision to blueprint. PLoS Biology, v.3, p.379-381, 2005.

RADAELLI, P.; FAJARDO, T.V.M.; NICKEL, O.; EIRAS, M.; PIO-RIBEIRO, G. Production of polyclonal antisera using recombinant coat proteins of Grapevine leafroll-associated virus 2 and Grapevine virus B. Pesquisa Agropecuária Brasileira, v.43, p.1405-1411, 2008.

SANGER, F.; NICKLEN, S.; COULSON, A.R. DNA sequencing with chain termination inhibitors. Proceedings of the National Academy of Sciences, v.74, p.5463-5467, 1977.

$\overline{\text { Recebido em } 27 \text { de abril de } 2010 \text { e aprovado em } 7 \text { de junho de } 2010}$ 